University of Nebraska - Lincoln

DigitalCommons@University of Nebraska - Lincoln

3-24-2005

\title{
Ordering Chaos: An Integrated Guide and Online Archive of Walt Whitman's Poetry Manuscripts
}

\author{
Brett Barney \\ University of Nebraska - Lincoln, bbarney2@unl.edu \\ Mary Ellen Ducey \\ University of Nebraska - Lincoln, mducey2@unl.edu \\ Andrew Jewell \\ University of Nebraska - Lincoln, ajewell2@unl.edu \\ Kenneth M. Price \\ University of Nebraska - Lincoln, kprice2@unl.edu \\ Brian L. Pytlik Zillig \\ University of Nebraska-Lincoln, bzillig1@unl.edu \\ See next page for additional authors
}

Follow this and additional works at: https://digitalcommons.unl.edu/libraryscience

Part of the Library and Information Science Commons

\footnotetext{
Barney, Brett; Ducey, Mary Ellen; Jewell, Andrew; Price, Kenneth M.; Pytlik Zillig, Brian L.; and Walter, Katherine L., "Ordering Chaos: An Integrated Guide and Online Archive of Walt Whitman's Poetry Manuscripts" (2005). Faculty Publications, UNL Libraries. 92.

https://digitalcommons.unl.edu/libraryscience/92
}

This Article is brought to you for free and open access by the Libraries at University of Nebraska-Lincoln at DigitalCommons@University of Nebraska - Lincoln. It has been accepted for inclusion in Faculty Publications, UNL Libraries by an authorized administrator of DigitalCommons@University of Nebraska - Lincoln. 


\section{Authors}

Brett Barney, Mary Ellen Ducey, Andrew Jewell, Kenneth M. Price, Brian L. Pytlik Zillig, and Katherine L. Walter 


\title{
Ordering Chaos: An Integrated Guide and Online Archive of Walt Whitman's Poetry Manuscripts
}

\author{
Brett Barney, Mary Ellen Ducey, Andrew Jewell, \\ Kenneth M. Price, Brian Pytlik Zillig, and Katherine L. Walter \\ University of Nebraska-Lincoln, USA
}

\section{Abstract}

In order to organize the widely dispersed manuscripts of Walt Whitman, The Walt Whitman Archive, in partnership with the University of NebraskaLincoln Libraries, has utilized the power of Encoded Archival Description (EAD) to create a single, scholarly enhanced guide to Whitman's poetry manuscripts. This integrated finding guide to Whitman's poetry manuscripts includes item-level description, links to repository guides that provide both location information and collection context, links to digital images of the manuscripts, and links to Text Encoding Initiative (TEI) transcriptions. In creating such a guide, we had to work cooperatively across disciplines and institutions, expand the use of EAD, and address how best to integrate description and transcription (EAD and TEI files). This essay describes our procedure as we created the integrated guide. From collecting finding aids and creating partnerships with other institutions, to developing a proper encoding standard and establishing good cross-department working relations, our project has embodied many of the benefits and challenges of digital work in the humanities. By identifying our procedures, and by laying out our future hurdles, we hope we can advance knowledge about Whitman and about how scholars and archivists can collaborate effectively to advance research, improve access, and realize the potential of EAD.

Correspondence:

Kenneth M. Price,

Department of English,

University of Nebraska-Lincoln,

PO Box 880333, Lincoln,

NE 68588-0333, USA.

E-mail:

kprice@unlnotes.unl.edu

\section{Introduction}

Visitors to Walt Whitman's home in Camden, New Jersey, described the poet, in his final years, as living in a tossed sea of scattered manuscripts that littered his floor. Despite the wealth of clutter, Whitman's home contained only part of the manuscript record. In fact, his manuscripts have never been all in one place. As early as 
his teenage years, Whitman had begun a practice of ceaselessly launching forth texts, sending out letters, essays, and poems to friends and publishers. When Whitman died, his literary executors did not consolidate his papers but instead contributed to their further dispersal. Currently, Whitman manuscripts are found in over seventy repositories, and Whitman scholars have been forced to travel widely to understand the depth and breadth of his manuscript legacy. The project we have undertaken, part of the Walt Whitman Archive, ${ }^{1}$ removes this barrier in Whitman scholarship. We are creating, in partnership with many institutions, a comprehensive guide to all Whitman manuscript materials, one place where a scholar, or any user, can go to search through the myriad documents and find exactly what is needed. In doing so, we are demonstrating the power of Encoded Archival Description (EAD) to pull together dispersed collections and create a single, scholarly-oriented view or collocation of the materials. We are also addressing an unresolved issue in digital scholarship, namely how best to integrate description and transcription (EAD and Text Encoding Initiative, TEI, files).

The Walt Whitman Archive strives to update, enhance, correct, and complete the work of our main print predecessor, the Collected Writings of Walt Whitman, published by New York University Press in twenty-two volumes from 1961 to 1984. The most glaring shortcoming of The Collected Writings is the omission of Whitman's manuscript notes and drafts for his poetry. Whitman left behind an extraordinary number of manuscripts, making it possible to track the development of his career-long work, Leaves of Grass. That is, it would be possible if these manuscripts were identified and accessible. Scattered in fragments in many archival repositories, these early drafts are irregularly and incompletely documented and catalogued, making it impossible for researchers to study systematically the origins of some of the most prized poetry ever produced in the United States.

The guide that the Walt Whitman Archive is creating integrates item-level information about all of Whitman's poetry manuscripts held in the USA and the UK. For Whitman studies, what is needed, and what we are in the process of providing, is a single index in which one can find all the various manuscript drafts, notebook versions, and corrected proofs of any single poem, indeed for all of his poems. Thanks to a seed grant from the Gladys Krieble Delmas Foundation, along with support from the University of Nebraska Research Council, the Whitman Archive first established the framework for this project at the University of Nebraska-Lincoln. Then, in partnership with the Institute for Advanced Technology in the Humanities at the University of Virginia (IATH), we sought and received major grant funding from the Institute of Museum and Library Services (IMLS) to support the more complete development of this work.

Although Whitman's manuscripts are widely scattered, most of them (approximately 80\%) can be found at a handful of collections

\section{The Walt Whitman}

Archive, http://www. whitmanarchive.org, co-edited by Ed Folsom of the University of Iowa and Kenneth M. Price of the University of NebraskaLincoln, was begun in 1995 and has had a long-standing affiliation with the Institute for Advanced Technology in the Humanities at the University of Virginia (IATH). A diverse and dispersed team (located primarily at the University of Iowa, University of Nebraska-Lincoln, University of Virginia, Duke University, and the University of North Carolina-Chapel Hill) is attempting to edit an even more radically dispersed set of manuscripts and printed materials through the cohering powers of advanced technology. John Unsworth, then-director of IATH, first suggested the idea of creating an integrated finding guide for Whitman's poetry manuscripts. Crucial guidance in pursuing this idea has been provided by Daniel Pitti, Project Director at IATH. 
at Duke University, University of Virginia, New York Public Library, University of Texas at Austin, and the Library of Congress. ${ }^{2}$ We have gathered finding aids and/or document images from these and a variety of other institutions, including the Boston Public Library, Boston University, Brown University, Mills College in Oakland, California, and the American Antiquarian Society, among others.

Our project makes use of EAD, which is a widely used standard for archival finding aids that facilitates sophisticated search and retrieval of manuscripts. Unlike TEI, which provides a standard for describing the structure and content of texts, EAD provides a standard for describing the structure and content of archival collections. For example, EAD employs elements that mark up the titles and dates of individual items (<unittitle> and <unitdate>), describe an item's substance $(<$ scopecontent $>$ ), and indicate the hierarchical structure of a collection (nested and numbered component, or $\langle\mathrm{c}\rangle$, tags). In some cases, our EAD files are based upon encoding already done by the holding repositories themselves; in other cases, we have created EAD files based upon paper records. Using EAD provides a means of gaining control of a wide variety of finding aids that are nearly as diverse as the Whitman materials that they describe. Moreover, EAD finding aids will serve as one of the many portals into the manuscript portion of the Whitman Archive.

An EAD finding aid produced with the active participation of scholars is needed because Whitman frequently left his manuscripts untitled, and when he did title them, he often used a title different from that employed in any of the six distinct editions of Leaves of Grass. It is thus difficult for anyone but specialists to correctly identify and categorize Whitman's manuscripts, a difficulty compounded by the fact that Whitman's poems sometimes began as prose jottings and only gradually evolved into verse. In other cases, a single manuscript may contain phrases or key images that appear in two different published

2 In advancing our EAD work, we have relied on developing strategic partnerships with Duke University, the University of Virginia, New York Public Library, the University of Texas at Austin, and the Library of Congress and have benefited from their cooperation and generosity. We excluded from our integrated guide the relatively few poetry manuscripts known to be in private hands because collectors, with security in mind, often do not wish to publicize their holdings. poems. Specialists can help to identify manuscripts that might look like prose but which are in fact the working papers contributing to poems, and they can help untangle complex genealogies.

The identification of manuscripts can be encoded into the EAD finding aid, enriching access and understanding for a wide network of archivists, scholars, and students. This is an important contribution, as it supplements traditional concerns of the archivist-provenance and original organization of the collection-with information of key importance to scholars. Archivists provide information about an item based on their knowledge of the object as an artifact and its place within a larger collection of documents. They cannot always be expected, nor do they always have the time, to put their holdings in a larger context, information that is often of great importance to the scholarly community. Scholars are more often able to provide this larger context based on their expertise and more frequent opportunities to focus on a particular topic. 
Our ultimate goal for the manuscript section of the Archive is to provide end users with crisp color images of manuscripts, reliable transcriptions encoded so as to facilitate scholarly analysis, and online union access through EAD to repository holdings, complete with links among these images, transcriptions, and descriptions. In short, we are providing more complete access to Whitman's poetry workshop than has ever before been possible. All finding aids uniquely produced for this project will be contributed to Research Libraries Group's Archival Resources to ensure the long-term availability of information to scholars and the public.

Our project builds upon work done by the American Heritage Virtual Archive and the Research Libraries Group. One of the goals of the American Heritage Virtual Archive (funded by the US National Endowment for the Humanities) was to integrate 'collections that have been dispersed among two or more institutions (such as the Mark Twain collections at Virginia and Berkeley)' and to experiment 'with cooperatively creating a single finding aid, in which separate components are used to describe each of the separate collections held at separate repositories' (American Heritage Project, 2000). However, because of its broad scope-American heritage materials of all sortsthe goal of creating a single, integrated finding aid was not reached. This remains an important research objective, and we believe that a project involving scholars with a focused interest in a more limited subject area, e.g. Whitman, rather than all of American heritage, can attain it.

A key component of our procedure has been the cultivation of partnerships, both within our institution, the University of NebraskaLincoln, and beyond it. At Nebraska, the key partnership between people from the English Department and the University Libraries resulted in an EAD Project Team. ${ }^{3}$ This team has developed finding aids that will satisfy the needs of Whitman scholars seeking precise information, in addition to providing information accessible to a general audience.

This double perspective shapes the type of finding aid we are developing. Our unified guide includes traditional finding aid information-creator, physical description, dates, scope and content, location, the title provided by the institution, and whether or not the item is handwritten. We have also included key information that will allow users to follow their own research interests through a straightforward, user-friendly finding aid that does not depend on having extensive experience in Whitman studies.

The components of the finding aid are based on required EAD elements, suggested elements from the EAD Cookbook (Fox, 2000), and follow the guidelines of the Research Libraries Group (RLG). The EAD elements also map to the USMARC format for bibliographic records. The EAD standard provides for great flexibility in the description of materials and the level of that description, and this flexibility has allowed us to choose to encode variations in titles, both the title on
3 From the English Department, Kenneth M. Price (Hillegass Professor of NineteenthCentury American Literature) and Andrew Jewell (a recent Ph.D. who works in conjunction with the initiative for Digital Research in the Humanities at the University of Nebraska-Lincoln); and from the University Libraries, Katherine Walter (Chair, Digital Initiatives and Special Collections), Mary Ellen Ducey (University Archivist), Brian Pytlik Zillig (Digital Initiatives Librarian), and Brett Barney (Research Assistant Professor, TEI specialist). 
4 Whitman authored six distinct editions of his masterwork, Leaves of Grass, throughout his lifetime, often revising and retitling individual poems for the new editions. The titles that appear in his final edition, the so-called Deathbed edition, published in 1892 , are the titles conventionally used in Whitman scholarship.

5 One part of our project addresses issues that are in some ways similar to those addressed by LEADERS (Linking EAD with Electronically Retrievable Sources), a project based at University College London and funded by the Arts and Humanities Research Board. There is much of interest and value in their approach, especially their use of Encoded Archival Context (EAC). They also offer one approach to integrating TEI and EAD. Their current practice involves expansion of the EAD header and removal of metadata from the TEI file. Their approach uses EAD for purposes it was not designed to meet and separates metadata from the data it describes, thus making problematic any possible future aggregation with other data sets. Our work is different from LEADERS in a couple of important ways. First, it adheres to accepted practice in the application of EAD. This is crucial because we are dealing with around thirty different collections, dispersed around the US and the UK. The LEADERS project, in contrast, deals with a single collection at their home institution. Unlike LEADERS, we are working collaboratively with other institutions, pulling in their the manuscript itself and, where it is different, the common or uniform title most familiar to readers-typically, the title Whitman used in the final version of Leaves of Grass. ${ }^{4}$ We have also chosen to encode supplemental information that will help users, including publication dates and manuscript dates, using a scheme that conforms to the practices of the Research Libraries Group (RLG). This dating scheme utilizes the potential of EAD's <unitdate> to offer the most accurate manuscript dating possible and to allow scholars to search and sort according to date. Typically, archivists provide dates that are gleaned, when possible, from the original manuscript. However, because of Whitman's predilection for writing on whatever scrap of paper was at hand and only rarely applying a date himself, archivists are usually left to make educated guesses. Our process allows us to revise these dates when appropriate, and EAD enables us to record our degree of certainty or uncertainty.

Scholars realize that Whitman finding aids can be greatly enhanced with additional information. Whitman was a compulsive reviser. An individual poem, for example, may exist in multiple manuscript drafts, a notebook, corrected page proofs, a periodical printing or printings, and in various forms in the editions of Leaves of Grass. And, as indicated above, in the early stages of their development, Whitman's drafts for poems often take the form of prose. In one case, a simple list of words offering different descriptions of mourning has been identified as a draft for Whitman's great elegy for Abraham Lincoln, 'When Lilacs Last in the Dooryard Bloom'd'. In such cases, specialists can help identify manuscripts that are in fact the working papers contributing to a poem.

This in-depth description can significantly increase the usefulness of a finding aid. At the completion of this project, assuming continuing cooperation from repositories, users ranging from advanced scholars to those reading Whitman for the first time will be able to electronically search through the world's collections of Whitman poetry manuscripts to find not only archival records for individual items, but also enhanced descriptions and digital images of the items themselves.

Our work would be painfully slow if not for a few key resources that enable us to complete the sort of description we desire quickly and reliably. When we come across a manuscript with an unusual title or no title at all, we employ Major Authors on CD-ROM: Walt Whitman (Folsom and Price, 1997). This CD, with its vast library of Whitman electronic text and its search function, allows us to search instantaneously through the poet's work and find connections between the sometimes very rough manuscript drafts and printed versions of poems, even if the manuscript contains only a few trial lines. Our ability to comb through Whitman's words has helped us to correct misattributions made in the past and has helped enable future scholarly work.

As indicated earlier, this type of detailed, item-level scholarly encoding of manuscripts is rare. ${ }^{5}$ Archival repositories prioritize 
work on collections based on money, staff availability, time, and the importance of the collection to the mission of the institution or the audience that a repository serves. Collections that have a high priority within the institution may merit item-level encoding, but this again is a choice based on limited resources. Most archival repositories are only able to describe collections at the container or folder level. Fortunately, grants received by the Whitman EAD Project have provided the time and staff to allow for item-level description.

The first collection we encoded, starting in the summer of 2001, was the Charles E. Feinberg Collection at the Library of Congress. This is the most extensive and important collection of Whitman material available for study. We prioritized it because its complexity presented many challenges to our development of EAD-encoded Whitman collections. One of the difficulties of our project was immediately evident: we had to describe items reliably and effectively while working at a distance from the physical artifacts themselves. Our EAD records for the Feinberg materials were created from microfilm facsimiles and digital images in conjunction with conversations with scholars who have worked closely with the originals. ${ }^{6}$

Typically, our item-level descriptions rely on two other sources: paper finding aids or catalogue cards provided by institutions, and images - usually high-quality digital images — of the original manuscripts. (Agreements with other institutions allow us to expand and revise their item-level descriptions of the manuscripts when necessary.) Our display of the finding aids privileges archival context. Users are constantly aware of where the manuscripts are in relation to the collection and archive in which they reside. We do not wish to create a detour around the various repositories of Whitman manuscripts but to make their holdings more accessible. The project will allow scholars to locate the manuscripts they are interested in with great precision, dissolving barriers (travel requirements, time, money) that have hindered work in Whitman manuscript studies. Moreover, it is now possible to bring together and compare high quality color facsimile images of manuscripts separated in two or more repositories. In the future, scholars will be able to answer many questions merely by having recourse to the integrated guide and the accompanying digital images. However, it would be shortsighted to suggest that this will bring an end to scholars' visits to rare book and manuscript repositories. On the contrary, the answering of some questions leads to the posing of others, and these additional questions in some cases will only be adequately addressed in the presence of the original artifacts. For example, providing transcriptions and facsimile images of Whitman's manuscripts enables scholars to address some questions about his habits of composition, but seeing these images can make one wonder about physical features of the artifacts, such as pinholes and embossing on stationary, that may hold clues to dating manuscripts and to the connections between intellectual units.
EAD work and using it in our own larger aggregation. In the course of our work we are creating something new, not digitizing something that already exists in another form. 6 In our work with Library of Congress materials (and elsewhere), we have been at pains to determine what is an 'item'. Our project's definition acknowledges the competing views of items as either intellectual or physical units, taking both into consideration but privileging the former. Specifically, we define a manuscript item as a discrete intellectual unit consisting of any number of physical objects. One item, say a poem made up of five leaves, might contain two or more intellectual units because of Whitman's habit of writing on the versos of letters, discarded envelopes, and assorted other lists and stray jottings. For example, a threepage draft of a poem is considered an item; so, too, is a single leaf that contains drafts of three separate poems; and so is a notebook containing an assortment of lists, poetic passages, and prose jottings. Our wish to honor boundaries between intellectual units for purposes of organization and transcription means that our policy differs from that of the Library of Congress and other repositories, which often simply group 'related' materials together as a single item. 
In an effort to create a highly usable research tool for those interested in Whitman's manuscripts, we realized early on that integration of the various EAD-encoded finding aids from each repository would be a highly desirable goal. We envisioned a process that would bring together many disparate parts of the Walt Whitman Archive through the creation of a unified guide. We are combining TEI transcriptions of manuscripts, digital images of the manuscripts, metadata about the creation of digital images, and EAD finding aids to create a single integrated collection of Whitman's poetry manuscripts. We want users to be able to search for a desired poem; to access a list of all original manuscripts related to that poem; and to view images, transcriptions, and the original location or repository of the manuscripts.

To accomplish the creation of the integrated finding aid, and to ensure consistency across our repository-level EAD encoded finding aids, model encoding practices were developed that clearly record all descriptive information we considered most valuable both for users and for the creators of the Whitman Archive, including the manuscript's title, the approximate date of composition, the number of leaves it comprises, and its relationship to Whitman's published work (see Appendix I). The need for item-level consistency in the encoding practices required us, with the cooperation of several institutions, to revise and to enhance many of the EAD finding aids that were created elsewhere. Revising other institutions' finding aids presented both intellectual and political challenges but was necessary in order to create the integrated finding aid.

Among those revisions was the insertion of two Walt Whitman Archive identifiers that facilitate links to transcriptions of poetry manuscripts, images of manuscripts, and metadata about images within the integrated guide. The first identifier, abbreviated WWA, corresponds to the project's transcription identifier, which is a unique string of characters assigned to each manuscript. Inserting this ID into the EAD finding aids for each poetry manuscript provides a means for linking item-level descriptions with transcriptions and manuscript images. (This linking brings together two distinct efforts-the work of creating a finding guide to poetry manuscripts and the work of transcribing those manuscripts.)

The second identifier is the work ID and will assist in organizing manuscripts based upon their relationships to one another and to Whitman's published work. Although the definition of work in the context of the project is highly nuanced, we are effectively making a distinction between a work, defined as the abstract idea of a poem that manifested itself in multiple ways in Whitman's life, and the instance of a work, defined as any handwritten or published version of the idealized poem. For example, all TEI-encoded versions of the work 'Song of Myself' -including the final version of the poem, an earlier published version entitled 'Poem of Walt Whitman, American', many manuscript and notebook fragments, and corrected page proofs-are connected to one another via the work ID. By attaching work IDs to the 
item-level information in the integrated guide, we provide a scheme whereby site visitors can use the most familiar published titles as a starting point for gathering all of the information regarding dispersed material that contributed to 'Song of Myself'.

Creating such an integrated guide requires overcoming numerous technical challenges. The key difficulty is that repositories implement $\mathrm{EAD}$ in significantly different ways because of the variance among collections and the materials within each collection, because of differing levels of description in various finding aids, and because of differing institutional encoding practices. Compiling the integrated guide depends upon the ability to create computer-readable instructions (using XSLT [eXtensible Stylesheet Language for Transformations]) to reliably navigate these differences, harvest the desired data relating to each poetry item from over thirty distinct EAD-encoded finding aids, and re-constitute that data in a uniform way.

Our computer-readable instructions complete three distinct transformations or processes. The first taps each encoded finding aid, the second connects to the work files to bring the uniform title into each item record for display purposes, and the final step presents the finding aid through HTML (see Appendix II). The integrated file, which adheres to EAD standards, is effectively a flat, unified version of many different files with significant differences in the EAD hierarchy and in the level of description. All item-level descriptions of poetry manuscripts are combined into one list, without additional hierarchical levels. Each item's date and physical description, a reference back to the original finding aid, and a link to the transcriptions and images are all maintained. ${ }^{7}$ This flattened EAD file will be used to present the integrated guide on the Walt Whitman Archive and is available (as a prototype) at http://www.whitmanarchive.org/manuscripts/

Successfully creating this integrated EAD guide is an exciting accomplishment for the project. Even so, much more work remains to be done. For example, we have constructed and are testing an apparatus that makes use of the work IDs to generate a level of hierarchy in the integrated file that is based not on repository-specific or physical relationships but on the intellectual relationships among the materials (see Appendix III). That is, we are striving to group together, under a uniform title, all of the manuscripts of a given poem, even when the manuscripts are untitled, titled variously, or have never been identified as contributing to a common work. When one manuscript contributes to multiple works, the description of that manuscript will be repeated and grouped with each appropriate work. We are also working to ensure that all non-poetry items are filtered out of the integrated guide, and we are experimenting with several alternatives for initiating the multiple transformations, weighing the costs and benefits among different combinations of dynamic and batch-processing. Once all of our work is done we expect to generate from the XML and XSLT files a static HTML page that can be delivered to users without lengthy processing delays and that incorporates recent revisions or
7 We used the $\mathrm{EAD}<$ dao $>$ tag to serve as the link between the item level description and the digital image of the item. 
enhancements made to the component XML files. One option that we are currently exploring is to run a PHP script to check the last revised date on each of the constituent files of the integrated guide. If any date is later than the existing compiled file, the integrated guide would be reconstituted before being delivered to a user. An alternative systemand one we are more likely to ultimately employ-would update the compiled files on a regular basis, say monthly or quarterly. All users would get the compiled file as it was generated for the current month or quarter.

Perhaps the most challenging aspect of the creation of the integrated guide is the implementation of a highly detailed and flexible search function, with an appealing interface, that can manipulate data and provide site visitors with the information they seek. Consideration of search options developed early in the project in order to ensure that the encoding would support future search mechanisms. For example, the encoding of title variants has been done in a way that makes them searchable. At this time, we are working with IATH to create a search interface that will allow experienced Whitman scholars, as well as new users, to find what they are looking for in a way that makes intuitive sense to someone inexperienced in archival research.

Although the priority now is to offer item-level description only for poetry manuscripts, some users will of course wish to supplement their research on poetry manuscripts with a study of the correspondence, journals and diaries, published works, or prose drafts. Some collections, such as the Feinberg Collection, are large enough to have been arranged into series. Other collections, Mills College, for example, contain only a few items. In addition, some collections, such as Stanford University's, have no poetry manuscripts at all. However, it is vital to make reference to these materials and repositories to provide an overview of the resources available for Whitman studies. One day we hope to complete this project with item-level description of all available Whitman materials.

From collecting finding aids and creating partnerships with other institutions, to developing a proper encoding standard and establishing good cross-department working relations, our project has embodied many of the benefits and challenges of digital work in the humanities. By identifying our procedures, and by laying out our future hurdles, we hope we can advance knowledge about Whitman and about how scholars and archivists can collaborate effectively to advance research, improve access, and realize the potential of EAD.

\section{References}

American Heritage Project (2000). American Heritage Virtual Archive Project: A Prototype 'Virtual Archive' of Encoded Finding Aids. Berkeley: University of California Regents. http://sunsite.berkeley.edu/amher/ (accessed 4 March 2004). 
Fox, M. J. (2000). The EAD Cookbook. ftp://jefferson.village.virginia.edu/pub/ ead/EADCookbook.pdf (accessed 4 March 2004).

Folsom, E. and Price, K. M. (1997). Major Authors on CD-ROM: Walt Whitman. Woodbridge, CT: Primary Source Media.

\section{Appendix I}

\section{Model encoding at the item level in repository-level finding guides}

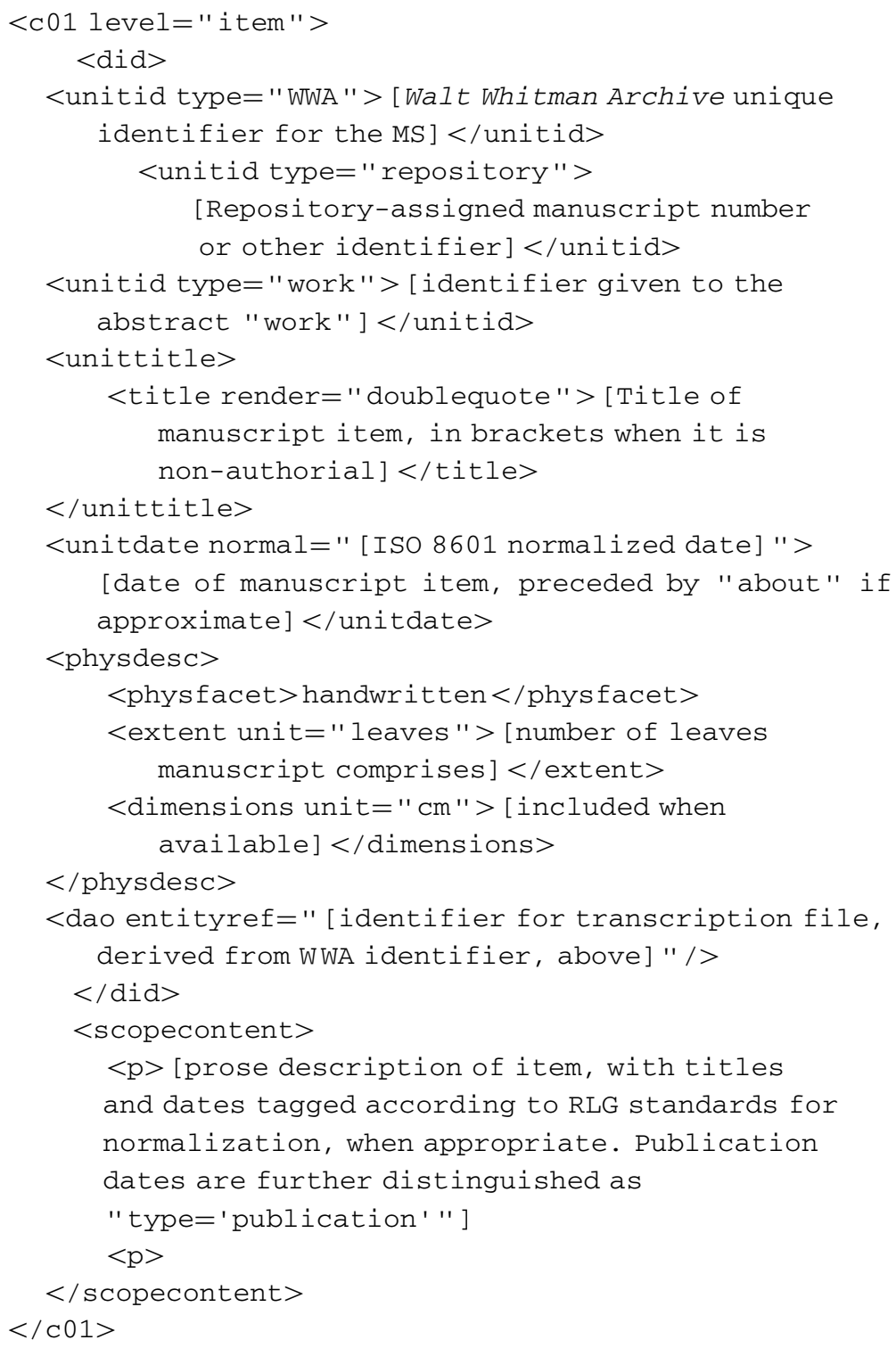

10 of 13 Literary and Linguistic Computing, 2005 


\section{Example of item description from the Yale Collection of American Literature, Beinecke Rare Book and Manuscript Library:}

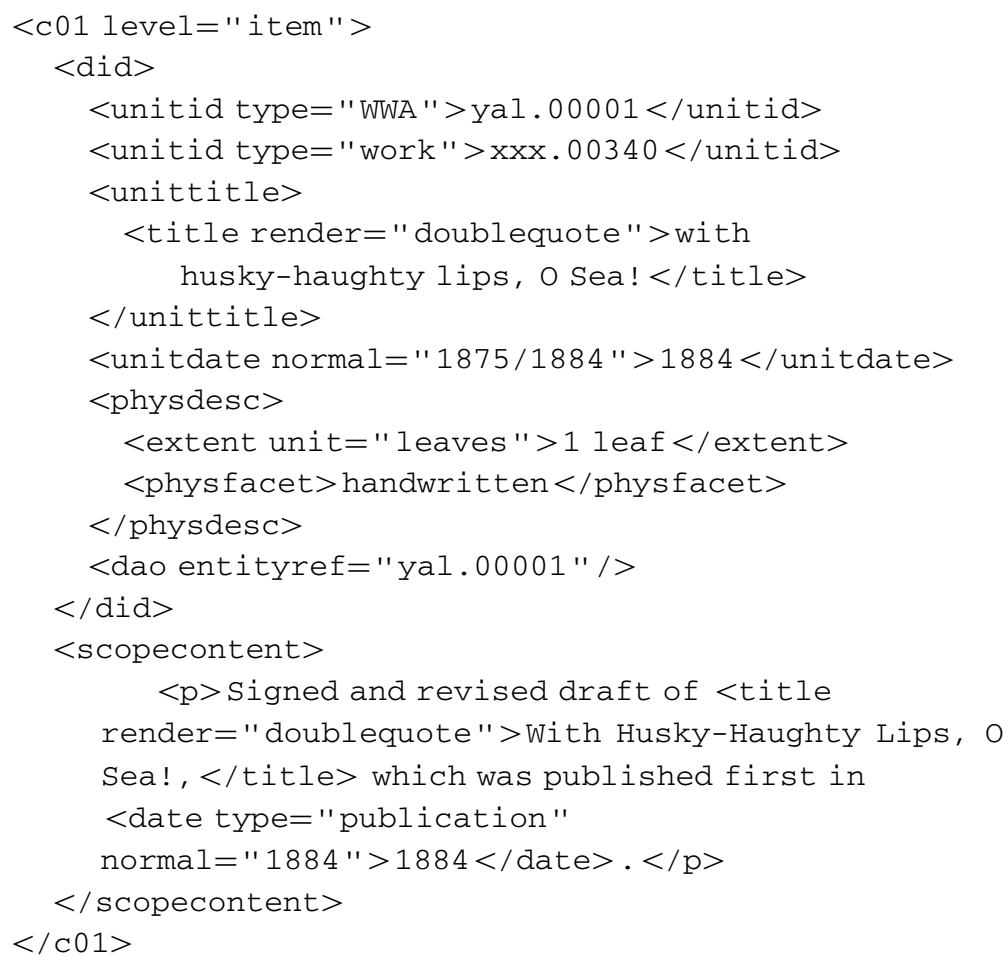

\section{Appendix II}

XSLT:

first stylesheet

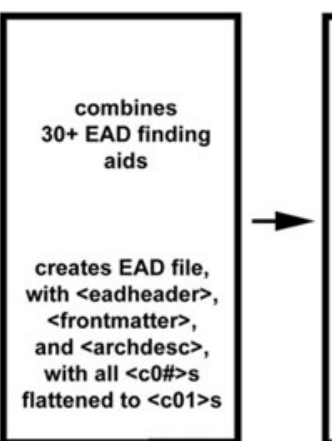

XSLT: second stylesheet

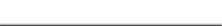
XSLT: third stylesheet

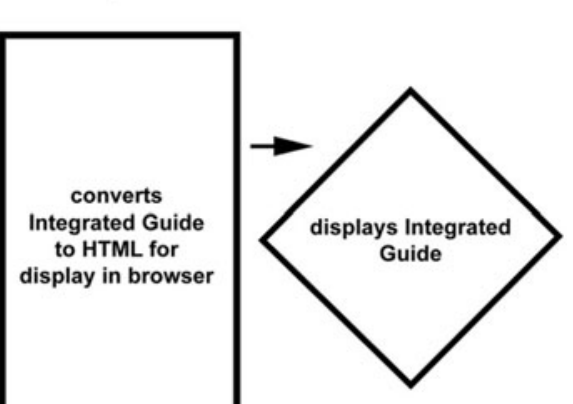

Integrated Guide to Walt Whitman's Poetry Manuscripts: the XSLT transformations. This graphic was originally prepared for an essay by Katherine Walter and Kenneth M. Price (2004), An Integrated Guide to Walt Whitman's Dispersed Manuscripts, Library Hi Tech, 22, 277-82. It is reused with permission. 


\section{Appendix III}

\section{Example of Integrated Guide Encoding}

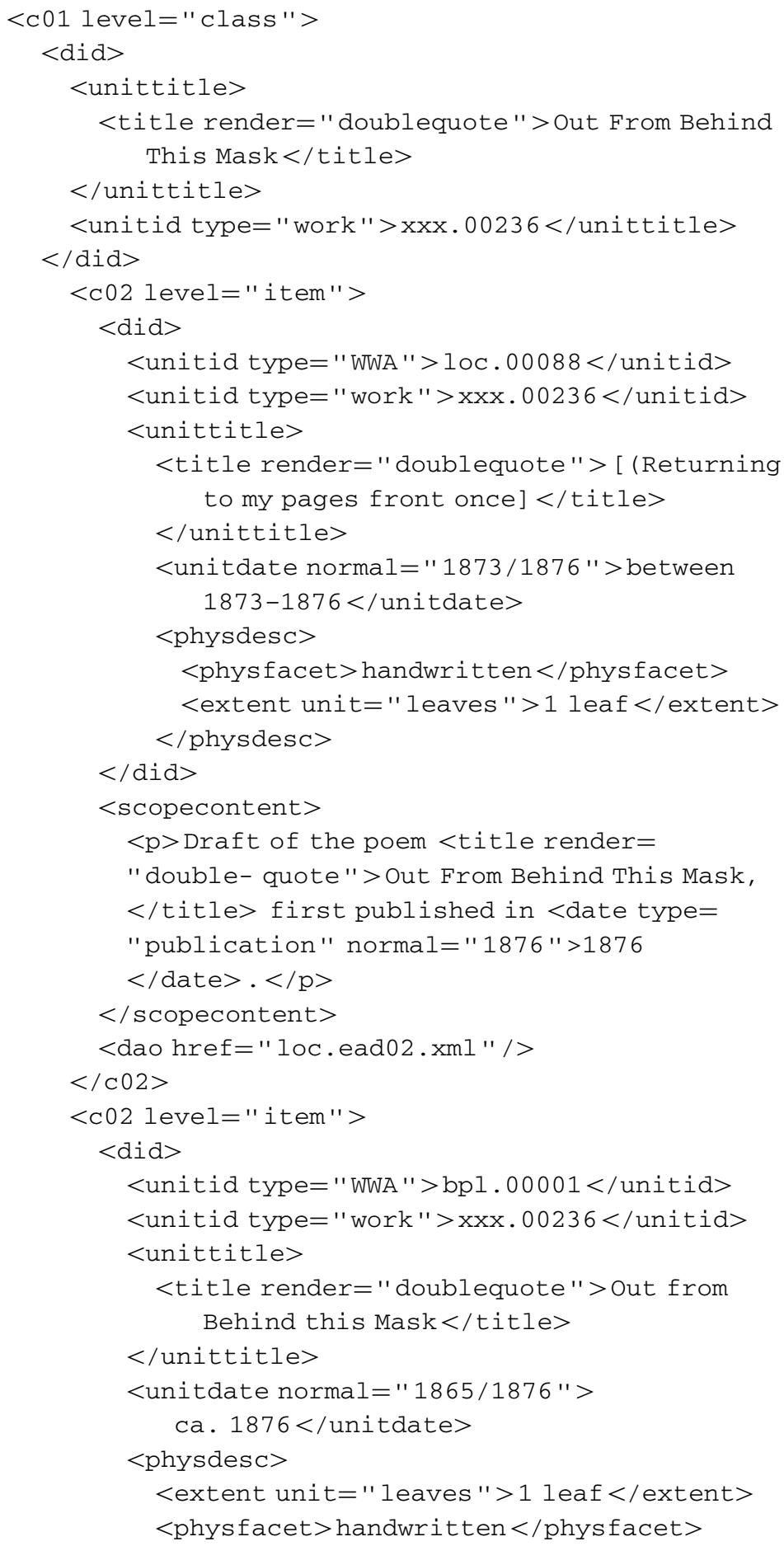

12 of 13 Literary and Linguistic Computing, 2005 


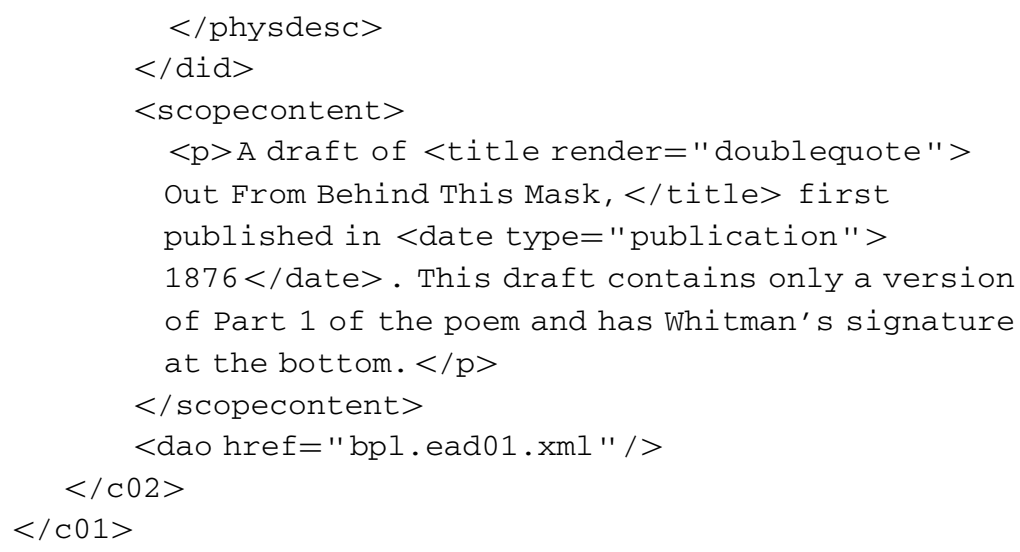

